\title{
TINGKAT PENGETAHUAN PENULISAN RESEP PADA MAHASISWA TINGKAT AKHIR TAHAP SARJANA PROGRAM STUDI KEDOKTERAN UNIVERSITAS MALAHAYATI
}

\author{
Mutiara Ghassani Pangestu ${ }^{1}$, Sri Maria Puji Lestari ${ }^{2^{*}}$, Esteria Marhayuni ${ }^{3}$, \\ Dessy Hermawan ${ }^{4}$
}

${ }^{1}$ Mahasiswa Program Studi Kedokteran Universitas Malahayati

${ }^{2}$ Departemen Pendidikan Dokter Fakultas Kedokteran Universitas Malahayati

${ }^{3}$ Departemen Parasitologi Fakultas Kedokteran Universitas Malahayati

${ }^{4}$ Departemen Keperawatan Fakultas Kedokteran Universitas Malahayati

Email Koresponden: srimaria13pl@yahoo.com

\begin{abstract}
KNOWLEDGE LEVEL OF RECEPTION WRITING AT END LEVEL BACHELOR STAGE BACHELOR OF MEDICAL STUDY PROGRAM, MALAHAYATI UNIVERSITY, 2020
\end{abstract}

Background: A prescription is one of the most important therapeutic transactions between $a$ doctor and a patient containing a written order about the drug to be used for the prevention of complications and the treatment of a patient diagnosis directed by the doctor. In determining medication and prescribing, a doctor should refer to the principles of rational therapy which include the right diagnosis or indication, the right selection and dosage form, the right method of administration and dosage, effective and safe and economical or affordable to the patient's ability. Final year medical students are students who have passed almost all clinical blocks, so prescription writing knowledge is quite good.

Objective: Determine the level of knowledge of prescription writing in the final year undergraduate students of the Malahayati University medical study program.

Method: The type of research used in this research is descriptive quantitative. With a measuring instrument using a questionnaire that has been tested for validity and reliability to the respondent.

Result: Of the 190 respondents consisting of 63 men and 127 women who filled out the questionnaire, the knowledge level of prescription writing was obtained (50.5\%) sufficient knowledge, (48.4\%) good knowledge and (1.1\%) lack of knowledge.

Conclusion: The majority of prescription writing knowledge of final year students of the Malahayati University medical study program has sufficient knowledge.

Keywords : Knowledge Level, Prescription Writing 


\section{INTISARI: TINGKAT PENGETAHUAN PENULISAN RESEP PADA MAHASISWA TINGKAT AKHIR TAHAP SARJANA PROGRAM STUDI KEDOKTERAN UNIVERSITAS MALAHAYATI}

Latar Belakang: Resep adalah salah satu transaksi terapeutik terpenting antara dokter dan pasien yang berisi perintah tertulis tentang obat yang akan digunakan untuk pencegahan komplikasi dan pengobatan diagnosis pasien yang diarahkan oleh dokter. Dalam menentukan pengobatan dan penulisan resep, seorang dokter hendaknya mengacu pada prinsip terapi rasional yang meliputi tepat diagnosis atau indikasi, tepat pemilihan dan bentuk sediaan obat, tepat cara pemberian dan dosis, manjur dan aman serta ekonomis atau terjangkau oleh kemampuan pasien. Mahasiswa kedokteran tingkat akhir adalah mahasiswa yang telah melewati hampir seluruh blok klinis, sehingga pengetahuan penulisan resep sudah cukup baik.

Tujuan: Mengetahui tingkat pengetahuan penulisan resep pada mahasiswa tingkat akhir tahap sarjana program studi kedokteran Universitas Malahayati.

Metode: Jenis penelitian yang digunakan dalam penelitian ini adalah deskriptif kuantitatif. Dengan alat ukur menggunakan kuesioner yang telah diuji validitas dan realibilitasnya kepada responden.

Hasil: Dari 190 responden yang terdiri dari 63 laki-laki dan 127 perempuan yang mengisi kuesioner tingkat pengetahuan penulisan resep didapatkan $(50,5 \%)$ pengetahuan cukup, $(48.4 \%)$ pengetahuan baik dan $(1,1 \%)$ pengetahuan kurang. Kesimpulan: Mayoritas pengetahuan penulisan resep mahasiswa tingkat akhir program studi kedokteran Universitas Malahayati memiliki pengetahuan cukup.

Kata Kunci : Tingkat Pengetahuan, Penulisan Resep

\section{PENDAHULUAN}

$\begin{array}{ccc}\text { Bila } & \text { seseorang mampu } \\ \text { menjawab } & \text { mengenai } & \text { materi }\end{array}$ tertentu baik secara lisan maupun tulisan, maka dikatakan seseorang tersebut mengetahui bidang tertentu. Sekumpulan jawaban yang diberikan tersebut dinamakan pengetahuan (Budiman dan Agus, 2013). Resep adalah suatu permintaan tertulis dari dokter, dokter gigi atau dokter hewan kepada apoteker untuk membuatkan obat dalam bentuk sediaan tertentu dan menyerahkannya kepada pasien (Panjaitan, 2017).

Berdasarkan WHO tahun 2016 yang tercermin dalam berbagai tingkat prevalensi kesalahan penulisan resep yang dilaporkan di berbagai belahan dunia. Di Inggris ditemukan $12 \%$ dari semua pasien perawatan primer meningkat menjadi $38 \%$ di usia 75 tahun ke atas dan $30 \%$ pada pasien yang menerima lima atau lebih obat selama periode 12 bulan. Secara keseluruhan, 5\% resep memiliki kesalahan resep. Di Swedia tingkat kesalahan $42 \%$. Sedangkan di Arab Saudi melaporkan bahwa hanya di bawah seperlima dari perawatan primer resep mengandung kesalahan, tetapi hanya sebagian kecil yang dianggap serius. Studi lain di Meksiko mengamati bahwa 58\% resep mengandung kesalahan, dengan regimen dosis terhitung untuk sebagian besar kasus $27,6 \%$.

Penelitian lain dilakukan oleh Mamarimbinnng et al (2012) tentang kelengkapan administrasi resep yang dituliskan oleh dokter anak di Kota Manado ialah Surat Izin Praktek (11,37\%), Alamat pasien $(53,7 \%)$, Jenis kelamin $(0 \%)$, Berat badan $(27,5 \%)$, Umur $(78,3 \%)$, tanggal penulisan resep (98.4\%) dan 
untuk tanda R/, Nama Dokter, Alamat Dokter, Paraf Dokter, Nama Pasien, Nama Obat, Dosis, Jumlah Obat, Cara pemakaian yang jelas (100\%). Dari data tersebut dapat disimpulkan dari tiga apotek di Kota Manado terdapat resep dokter spesialis anak yang berpotensi terjadi kesalahan penulisan resep dan tidak ditemukan satupun resep yang memenuhi kriteria skrining dalam kelengkapan administrasi resep berdasarkan Surat Keputusan Menteri Kesehatan no.1027/MENKES/SK/1X/2004.

Di Indonesia gelar profesi dokter didapatkan melalui seleksi Uji Kompetensi Mahasiswa Program Profesi Dokter (UKMPPD). UKMPPD terdiri dari dua metode ujian ialah Computer Based Test (CBT) dan ujian Objective Structured Clinical Examination (OSCE). ). Tatalaksana farmakologi merupakan satu dari berbagai aspek kompetensi dokter yang juga dinilai pada ujian OSCE. Ujian OSCE dinilai untuk membedakan subyek yang berkompetensi dan yang tidak memiliki kompetensi (Konsil Kedokteran Indonesia, 2019).

$$
\text { Berdasarkan data dari }
$$

Kemendikbud dari Agustus 2014 sampai Mei 2018, terdapat kurang lebih 39.000 dokter yang dinyatakan lulus UKMPPD dan tersisa kurang lebih 2400 retaker $(<8 \%$ dari jumlah peserta yang mengikuti UKMPPD). Di sisi lain, terjadi kenaikan yang signifikan pada persentase kelulusan UKMPPD. Dengan Nilai Batas Lulus 66\%, di tahun 2014 kelulusan 1st taker adalah $67 \%$ dan meningkat pada akhir 2017 menjadi 73\%, dan terutama pada periode Mei 2018 mencapai > 80 \% (Ristekdikti, 2018).

Penelitian yang dilakukan Melviana (2019) dari 10 station OSCE UKMPPD yang mengujikan kompetensi farmakologi, didapatkan hanya $7,7 \%$ mahasiswa yang mendapat nilai sempurna untuk kompetensi farmakologi. Sedangkan sebagian besar lainnya mampu mendiagnosis namun salah dalam menetapkan terapi $(34,1 \%)$ dan sebanyak 28,1\% mahasiswa mampu menetapkan terapi yang sesuai namun salah dalam memilih dosis atau frekuensi pemberian.

Penelitian yang dilakukan oleh Pratiwi et al (2017) menyatakan dari 262 responden penilaian terhadap mutu pelayanan di Instalasi farmasi diperoleh 165 responden $(62,98 \%)$ dalam pemberian obat pada pasien rawat jalan peserta JKN belum 100\% mengacu pada formularium nasional sesuai dengan standar pelayanan minimal. Terdapat perbedaan berarti antara kesamaan penulisan resep dengan formularium akan kualitas pelayanan. Semakin tinggi bagian kemiripan resep dengan formularium nasional di RS hingga kualitas pelayanan instalasi farmasi akan membaik.

Penulisan resep juga merupakan bagian dari kurikulum mahasiswa kedokteran, keterampilan meresepkan mereka masih buruk baik sebagai bagian dari ujian mereka atau saat mereka keluar sebagai tenaga Kesehatan yang berkualitas yg mungkin disebabkan oleh pelatihan yang tidak memadai (Thenrajan dan Murugan, 2016). Sesuai dengan penelitian yang dilaksanakan oleh Oktarlina dan Ariyanti (2019) di Fakultas Kedokteran Universitas Lampung yang meneliti tentang pengetahuan mahasiswa mengenai penulisan resep pada mahasiswa tingkat 4 dari 136 responden didapatkan hasil rata- rata pengetahuan mahasiswa dalam penulisan resep secara baik dan benar berada pada kategori baik yaitu berjumlah 80 responden $(58,8 \%)$, pengetahuan cukup sebanyak 45 responden $(33,1 \%)$ dan pengetahuan kurang sebanyak 11 
responden $(8,1 \%)$.

Berdasarkan data yang ada, masih banyak kesalahan dalam penulisan resep di kalangan calon dokter, dokter serta apoteker baik dari segi tulisan atau dalam segi mempraktikkan format penulisan resep dengan tepat. Sedangkan di Universitas Malahayati sendiri belum ada penelitian mengenai tingkat pengetahuan penulisan resep pada mahasiswa kedokteran. Mahasiswa kedokteran tingkat akhir adalah mahasiswa yang telah melewati hampir seluruh blok klinis, sehingga pengetahuan penulisan resep sudah cukup baik.

\section{METODE}

Penelitian ini menggunakan jenis kuantitatif dengan metode deskriptif karena data diperoleh melalui pengukuran terhadap fenomena dari subyek penelitian. Penelitian telah dilaksanakan pada bulan Desember 2020 - Januari 2021. Penelitian dilakukan menggunakan Zoom Meetings. Populasi yang digunakan dalam penelitian ini adalah mahasiswa tingkat akhir tahap sarjana program studi kedokteran Universitas Malahayati tahun 2020/2021.

Sampel yang digunakan pada penelitian ini 190 mahasiswa. Teknik yang digunakan pada penelitian ini adalah purposive sampling. Dimana pengumpulan sampel dengan cara purposive berlandaskan pada suatu pandangan tertentu yang dibuat oleh peneliti, menuruti ciri atau karakter populasi yang telah diketahui sebelumnya (Notoatmodjo, 2018:125) dengan rumus Slovin dengan margin of error 5\% dari 324 mahasiswa tingkat akhir tahap sarjana program studi kedokteran Universitas Malahayati dengan cara:

Rumus Slovin

$$
n=\frac{N}{1+N e^{2}}
$$

$\mathrm{N}$ : besar populasi/jumlah

populasi

$\mathrm{N} \quad$ : jumlah sample

E : batas toleransi kesalahan

(error tolerance)

(Sujarweni, 2019:66).

Dengan hasil yaitu 190 mahasiswa terdiri dari 63 laki-laki dan 127 perempuan untuk mewakilkan masing-masing gender pada populasi.

Alat ukur penelitian ini adalah kuesioner berskala Guttman. Kuesioner berjumlah sebanyak 33 pertanyaan, terdiri dari 21 pertanyaan favorable dan 12 pertanyaan unfavorable. Data yang ditemukan pada kuesioner ini berupa data nominal yaitu "Benar" dan "Salah". Pada pertanyaan favorable jawaban benar $=1$ dan salah $=0$, sedangkan unfavorable jawaban benar $=0$ dan salah $=1$. Dengan hasil ukur kuesioner 2 = baik $76 \%-100 \%$, 1 = cukup $55 \%-75 \%$, dan 0 $=$ kurang $<55 \%$.

kuesioner ini telah dilakukan uji validitas dan reliabilitas sebelum digunakan pada penelitian. Uji validitas dilakukan memakai koefisien Reprodusibilitas dan koefisien Skalabilitas, Dengan rumus (Munggaran, 2012):

Koefisien Reprodusibilitas $(K r)$

Keterangan :

$$
K r=1-\frac{e}{n}
$$

$\mathrm{Kr} \quad=$ Koefisien Reprodusibilitas

$e \quad=$ jumlah kesalahan

$n=$ jumlah total pilihan jawaban $=$ jumlah pertanyaan $\mathrm{x}$ jumlah responden

Koefisien Skalabilitas (Ks)

Keterangan :

$$
K s=1-\frac{e}{c n-T n}
$$

Ks = Koefisien Skalabilitas

$e \quad=$ Jumlah kesalahan

$\mathrm{k}=$ Jumlah kesalahan yang diharapkan $=\mathrm{c}(\mathrm{n}-\mathrm{Tn})$ dimana $\mathrm{c}$ adalah kemungkinan mendapatkan jawaban yang benar. Karena jawaban adalah "Ya" dan "Tidak" 
maka $c=0,5$.

$\mathrm{n}=$ jumlah total pilihan jawaban = jumlah pertanyaan $\mathrm{x}$ jumlah responden

Tn = jumlah pilihan jawaban Setelah dilakukan uji instrumen penelitian, didapatkan hasil dari 34 responden dengan jumlah potensi salah sebesar 1122 dan jumlah error 214, dengan koefisien Reprodusibilitas bernilai 0,81 dan koefisien Skalabilitas sebesar 0,61.

Skala dengan nilai $K r>0,90$
dianggap validitas tinggi

(Munggaran, 2012). Dan nilai dari perhitungan ini 0,81 maka Koefisien Reprodusibilitas untuk hasil uji coba ini dianggap mencapai nilai $K r$ yang cukup valid. Jika nilai Ks (koefisien skalabilitas) > 0,60 bahwa dianggap validitas tinggi untuk digunakan dalam penelitian. Dan nilai dari perhitungan ini 0,61 maka Koefisien Skalabilitas untuk hasil uji coba ini dianggap validitas tinggi guna penelitian.

Uji reliabilitas dikerjakan dengan memanfaatkan KR 20 (Kuder Richardson), dengan rumus (Munggaran, 2012):

$$
r i=\frac{k}{k-1} \frac{S_{t}^{2}-\sum p i q i}{S_{t}^{2}}
$$

Keterangan :

$\mathrm{k}=$ jumlah item dalam instrumen

$p i \quad=$ proporsi banyaknya subjek yang menjawab pada item 1

$q i \quad=1-p i$

$s_{t}^{2} \quad=$ varians total

Maka didapatkan hasil uji reabilitas sebesar 0,71 lalu dimasukkan kedalam tebel kriteria reabilitas. Hasil hitung menunjukan intrumen memiliki reliabilitas tinggi untuk digunakan dalam penelitian.

\section{HASIL DAN PEMBAHASAN}

Data yang digunakan pada penelitian ini adalah data hasil pengisian kuesioner oleh mahasiswa tingkat akhir tahap sarjana program studi kedokteran Universitas Malahayati pada 28 Desember 2020 sampai 6 Januari 2021 melalui Zoom Meetings. Dengan memperhatikan kriteria inklusi dan eksklusi, didapatkan jumlah sampel sebanyak 190 responden. Dengan hasil sebagai berikut:

Tabel 1 Distribusi Frekuensi Responden Penelitian Berdasarkan Usia

\begin{tabular}{ccc}
\hline Usia & Frekuensi & $\%$ \\
\hline 19 & 1 & 0,5 \\
20 & 31 & 16,3 \\
21 & 99 & $\mathbf{5 2 , 1}$ \\
22 & 47 & 24,7 \\
23 & 10 & 5,3 \\
24 & 1 & 0,5 \\
25 & 1 & 0,5 \\
\hline Total & 190 & 100 \\
\hline
\end{tabular}

Berdasarkan tabel 1 hasil responden berusia 21 tahun $(52,1 \%)$. menunjukkan bahwa mayoritas

Tabel 2 Distribusi Frekuensi Responden Berdasarkan Jenis Kelamin

\begin{tabular}{ccc}
\hline Jenis Kelamin & Jumlah & $\%$ \\
\hline Perempuan & 127 & 66.8 \\
Laki-laki & 63 & 33.2 \\
\hline Jumlah & 190 & 100 \\
\hline
\end{tabular}


Dari tabel 2 di atas dapat dilihat sebagian besar responden berjenis kelamin perempuan sebanyak 127 orang (66.8\%).

Tabel 3 Distribusi Frekuensi Tingkat Pengetahuan

\begin{tabular}{cccc}
\hline & Kategorik & Frekuensi & $\%$ \\
\hline Tingkat & Baik & 92 & 48.4 \\
Pengetahuan & Cukup & 96 & 50.5 \\
& Kurang & 2 & 1.1 \\
\hline Jumlah & & 190 & 100 \\
\hline
\end{tabular}

Dari tabel 3 di atas menunjukkan mayoritas seluruh responden berpengetahuan cukup sebanyak 96 orang (50.5\%).

Tabel 4 Distribusi Frekuensi Tingkat Pengetahuan Berdasarkan Jenis Kelamin

\begin{tabular}{cccccc} 
& Kategorik & \multicolumn{2}{c}{ Laki-laki } & \multicolumn{2}{c}{ Perempuan } \\
& & Frek & $\%$ & Frek & $\%$ \\
\hline Tingkat & Baik & 24 & 38.1 & 68 & 53.5 \\
Pengetahuan & Cukup & 38 & 60.3 & 58 & 45.7 \\
& Kurang & 1 & 1.6 & 1 & 0.8 \\
\hline Jumlah & & 63 & 100 & 127 & 100 \\
\hline
\end{tabular}

Dari tabel 4 di atas menunjukkan mayoritas responden pengetahuan perempuan lebih baik

dari pada laki-laki yaitu berpengetahuan baik sebanyak 68 orang $(53.5 \%)$.

Tabel 5 Distribusi Frekuensi Responden Tingkat Pengetahuan Berdasarkan Topik Pembahasan

\begin{tabular}{cccc}
\hline & Kategorik & Frekuensi & $\%$ \\
\hline Topik definisi & Baik & 184 & 96.8 \\
resep & Cukup & 0 & 0 \\
& Kurang & 6 & 3.2 \\
\hline Jumlah & & 190 & 100 \\
\hline Topik jenis & Baik & 158 & 83.2 \\
resep & Cukup & 29 & 15.3 \\
& Kurang & 3 & 1.6 \\
\hline Jumlah & & 190 & 100 \\
\hline Topik format & Baik & 110 & 57.9 \\
resep & Cukup & 71 & 37.4 \\
& Kurang & 9 & 4.7 \\
\hline Jumlah & & 190 & 100 \\
\hline Topik tanda & Baik & 174 & 91.6 \\
pada resep & Cukup & 15 & 7.9 \\
& Kurang & 1 & 0.5 \\
\hline Jumlah & & 190 & 100 \\
\hline Topik & Baik & 70 & 36.8 \\
Singkatan & Cukup & 114 & 60 \\
Peresepan & Kurang & 6 & 3.2 \\
\hline Jumlah & & 190 & 100 \\
\hline Topik penulisan & Baik & 143 & 75.3 \\
resep & Cukup & 44 & 23.2 \\
& Kurang & 3 & 1.5 \\
\hline
\end{tabular}




\begin{tabular}{cccc} 
Jumlah & & 190 & 100 \\
\hline Topik & Baik & 190 & 100 \\
wewenang & Cukup & 0 & 0 \\
menulis resep & Kurang & 0 & 0 \\
\hline Jumlah & & 190 & 100 \\
\hline
\end{tabular}

Dari tabel 4 di atas menunjukkan mayoritas Topik yang sangat dikuasai adalah topik wewenang menulis resep dengan seluruh responden memiliki pengetahuan baik (100\%), sedangkan topik yang kurang dikuasai topik singkatan pada resep dengan mayoritas seluruh responden memiliki pengetahuan baik sebanyak 70 orang $(36.8 \%)$.
Untuk mengetahui variabel peneliti berdistribusi normal atau tidak normal maka dilakukan uji normalitas dengan uji KolmogorovSmirnov dengan nilai $\mathrm{p}>0,05$ normal dan $\mathrm{p}<0,05$ tidak normal. Hasil uji Kolmogorov-Smirnov menunjukkan sig 0.003 dimana kurang dari 0.05 , hal ini menunjukkan sebaran data tidak berdistribusi normal atau diambil dari populasi tidak normal.

Table 6 Distribusi Frekuensi Responden Berdasarkan skor Kuesioner

\begin{tabular}{ccccc}
\hline Jawaban benar & $\mathrm{N}$ & Median & Min & Maks \\
\hline Seluruh & 190 & 24.00 & 17 & 32 \\
Laki-laki & 63 & 24.00 & 17 & 32 \\
Perempuan & 127 & 25.00 & 18 & 31 \\
\hline
\end{tabular}

Dari tabel 4.6 di atas menunjukkan nilai tertinggi responden adalah 32 jawaban benar

\section{PEMBAHASAN}

\section{a. Karakteristik Responden} Hasil penelitian mahasiswa tingkat akhir program studi kedokteran sebagian besar responden yang mengisi kuesioner berjenis kelamin perempuan sebanyak 127 orang (66.8\%). Sedangkan pada usia menunjukkan bahwa mayoritas mahasiswa tingkat akhir tahap sarjana program studi kedokteran Universitas Malahayati berusia 21 tahun (52,1\%). Menurut Elizabeth B. Hurlock Masa dewasa awal berkisar antara umur 21 sampai 40 tahun (Maulidya, 2018). Menunjukan mahasiswa tingkat akhir tahap sarjana program studi kedokteran Universitas Malahayati merupakan masa dewasa awal. dan terendah adalah 17 jawaban benar dengan nilai median seluruh responden adalah 24.00 .

\section{b. Tingkat Pengetahuan Penulisan Resep}

Tingkat pengetahuan penulisan resep dikategorikan menjadi pengetahuan baik $(\geq 75 \%$ jawaban benar), pengetahuan cukup (56-74\% jawaban benar), dan pengetahuan kurang $(\leq 55 \%$ jawaban benar) (Budiman dan Agus ,2013). Dari 190 responden yang mengisi kuesioner tingkat pengetahuan penulisan resep didapatkan $(50,5 \%)$ pengetahuan cukup, (48.4\%) pengetahuan baik dan $(1,1 \%)$ pengetahuan kurang. Sedangkan jawaban benar seluruh responden dengan median 24.00, nilai minimal 17 jawaban benar dan nilai maksimal 32 jawaban benar. Maka mayoritas mahasiswa tingkat akhir program studi kedokteran Universitas Malahayati memiliki pengetahuan cukup pada penulisan resep dengan 
median 24.00.

Pengetahuan sendiri menurut Skinner, bila seseorang mampu menjawab mengenai materi tertentu baik secara lisan maupun tulisan, maka dikatakan seseorang tersebut mengetahui bidang tertentu. Pengetahuan seseorang terdiri dari 3 bobot, yaitu bobot I tahap tahu dan pemahaman, tahap II tahap tahu, pemahaman, aplikasi dan analisis, tahap III tahap tahu, pemahaman, aplikasi, analisis, sintesis, dan evaluasi (Budiman dan Agus ,2013). Hasil penelitian ini hampir sejalan dengan penelitian Oktarlina dan Ariyanti (2019) pada mahasiswa kedokteran tingkat 4 Universitas Lampung dimana bahwa mayoritas mahasiswa memiliki tingkat pengetahuan baik dan hanya sedikit mahasiswa dengan pengetahuan cukup.

\section{c. Tingkat Pengetahuan Berdasarkan Jenis kelamin Pada penelitian ini responden terdiri 63 laki-laki dan 127 perempuan. Tingkat} pengetahuan berdasarkan jenis kelamin, pada responden laki-laki terdapat $(38,1 \%)$ pengetahuan baik, $(60,3 \%)$ pengetahuan cukup dan $(1,6 \%)$ pengetahuan kurang, sedangkan pada perempuan terdapat $(53,5 \%)$ pengetahuan baik dan $(45,7 \%)$ pengetahuan cukup dan $(0,8 \%)$ pengetahuan kurang. Sedangkan berdasarkan jawaban benar responden pada laki-laki nilai median 24.00, nilai minimal 17 jawaban benar, dan nilai maksimal 32 jawaban benar. Sedangkan pada perempuan nilai median 25.00 , nilai minimal 18 jawaban benar dan nilai maksimal 31 jawaban benar. Dari hasil penelitian didapatkan bahwa responden perempuan memiliki pengetahuan lebih baik dibandingkan laki-laki yaitu berpengetahuan baik sebanyak 68 orang (53.5\%).
Perempuan pada umumnya lebih akurat dan lebih mendetail. Mayoritas Mahasiswi akan membuat catatan dan diktat-diktat perkuliahan yang lebih lengkap dan teliti daripada mahasiswa laki-laki. Dan perempuan mempunyai sifat rajin dimana hal ini akan membuat kemampuan berpikir kreatif perempuan lebih baik daripada lakilaki (Yumniyati, 2016). Prestasi sekolah perempuan dinilai lebih konsisten dari pada laki-laki, secara konsisten perempuan mengerjakan tugas verbal lebih baik dari laki-laki, sehingga menempatkan perempuan di posisi teratas dalam prestasi (Sugianto dan Lisiswanti, 2016).

\section{d. Tingkat Mahasiswa pada Topik Pembahasan} Pada topik definisi resep didapatkan $(96,8 \%) \quad$ dengan pengetahuan baik dan $(3,2 \%)$ pengetahuan kurang. Dan pada topik jenis-jenis resep didapatkan $(83,2 \%)$ pengetahuan baik, (15,3\%) pengetahuan cukup dan $(1,6 \%)$ pengetahuan kuran. Pada topik format peresepan terdapat $(57,9 \%)$ pengetahuan baik, $(37,4 \%)$ pengetahuan cukup dan $(4,7 \%)$ pengetahuan kurang. Sedangkan topik tanda-tanda pada resep didapatkan $(91,6 \%)$ pengetahuan baik, $(7,9 \%)$ pengetahuan cukup dan $(0,5 \%)$ pengetahuan kurang. Pada topik singkatan peresepan didapatkan $(36,8 \%)$ pengetahuan baik, $(60 \%)$ pengetahuan cukup dan $(3,2 \%)$ pengetahuan kurang. Sedangkan topik penulisan resep yang rasional didapatkan $(75,3 \%)$ pengetahuan baik, $(23,2 \%)$ pengetahuan cukup dan $(1,6 \%)$ pengetahuan kurang. Dan topik wewenang menulis resep didapatkan hasil $(100 \%)$ responden memiliki pengetahuan baik. Maka topik yang sangat dikuasai oleh mahasiswa tingkat akhir adalah wewenang 
menulis resep $(100 \%)$. Sedangkan topik yang kurang dikuasai adalah singkatan peresepan yaitu hanya $(36,8 \%)$.

Penulisan resep adalah suatu wujud akhir kompetensi dokter dalam pelayanan kesehatan yang secara komprehensif dalam menerapkan ilmu pengetahuan dan keahlian di bidang farmakologi dan teraupetik secara tepat, aman dan benar kepada pasien. Sebagian obat tidak dapat diberikan langsung kepada pasien atau masyarakat melainkan harus melalui peresepan oleh dokter (Panjaitan, 2017). Kesalahan penulisan resep yang sering terjadi adalah tidak diberikannya informasi, penulisan resep yang buruk dan pembuatan

\section{KESIMPULAN DAN SARAN}

Berdasarkan analisis data hasil penelitian mengenai tingkat pengetahuan penulisan resep pada mahasiswa tingkat akhir tahap sarjana program studi kedokteran Universitas Malahayati tahun 2020 diperoleh kesimpulan sebagai berikut:

a. Sebagian besar responden memiliki pengetahuan cukup $(50,5 \%)$ dengan median jawaban benar 24.00 .

b. Mayoritas responden perempuan memiliki pengetahuan lebih baik dari pada laki-laki yaitu berpengetahuan baik (53,5\%) dengan nilai median jawaban benar 25.00 .

c. Topik bahasan yang mayoritas sangat dikuasai responden adalah wewenang menulis resep $(100 \%)$ pengetahuan baik dan yang kurang dikuasai adalah singkatan peresepan (36.8\%) pengetahuan baik.

Bagi Mahasiswa sebagai Responden Hasil penelitian ini dapat digunakan sebagai pengetahuan mengenai resep yang tidak sesuai (Katzung, 2017). Hasil penelitian ini sejalan dengan penelitian Mamarimbing et al (2012) pada resep dokter spesialis anak di 3 apotek Kota Manado tidak ditemukan satupun resep yang memenuhi kriteria skrining. Semua itu dapat berakibat fatal pada pengobatan pasien. Dan dari hasil penelitian di atas peneliti berpendapat bahwa jika seorang dokter menguasai materi dasar penulisan resep seperti format, tanda serta singkatan peresepan maka dapat mengurangi resiko kesalahan penulisan resep dan kesalahan pemberiaan obat kepada pasien baik dalam rawat jalan maupun rawat inap.

definisi resep, jenis-jenis resep, format resep, tanda-tanda pada resep, singkatan peresepan, penulisan resep yang rasional dan wewenang menulis resep. Selain itu, dapat diaplikasikan oleh para calon dokter dan dokter dalam menulis resep yang baik.

\section{Bagi Institusi Pendidikan}

Dapat menambah studi kepustakaan terutama yang berkaitan dengan penulisan resep dan dapat meningkatkan pembelajaran mengenai singkatan peresepan atau topik yang kurang dikuasai oleh mahasiswa serta diharapkan menjadi masukan yang bermanfaat bagi mahasiswa Prodi Kedokteran Umum Fakultas kedokteran.

\section{Bagi Peneliti Selanjutnya}

Agar dapat melakukan penelitian bivariat atau multivariat sehingga dapat membandingkan tiap variabel dan desain studi epidemiologi yang lebih kuat, yaitu case control atau cohort sehingga besar resiko masingmasing variabel dapat diukur lebih jelas. 


\section{DAFTAR PUSTAKA}

Ajay, K., Saurabh, J., Dangi, I., Chowdary, S., Choubitker, Omprakash Kumar, P. K., \& R.S., P. (2019). 4. Ideal drug prescription writing. World Journal of Pharmacy and Pharmaceutical Sciences, 8(March), 634-654. https://doi.org/ 10.20959/wj pps20193-12989

Budiman, Agus, R. (2013). Kapita Selekta Kuesioner Pengetahuan dan Sikap dalam Penelitian Kesehatan. Jakarta: Salemba Medika.

Katzung, B. G. (2017). Farmakologi Dasar dan Klinik Edisi 12 Volume 2. Jakarta : EGC.

Konsil Kedokteran Indonesia. (2019). Standar Nasional Program Profesi Dokter Indonesia. 247.

Mamarimbing, M., Fatimawali dan Bodhi, W. (2012). Evaluasi Kelengkapan Resep dari Dokter Spesialis Anak padaTiga Apotek di Kota Manado. Journal of Pharmachon, Vol 1(2), 45-51. https://ejournal.unsrat.ac.id /index.php/pharmacon/artic le/viewFile/485/378\%0A

Maulidya, F., Adelina, M., Hidayat F.A. (2018). Periodesasi

Perkembangan

Dewasa. Periodesasi

Perkembangan Dewasa. pp. 110.

Melviana. (2019). Analisis dan Eksplorasi Kompetensi Tatalaksana Farmakologi Mahasiswa pada Ujian Simulasi OSCE UKMPPD di Fakultas Kedokteran Universitas Muhammadiyah Sumatera Utara. Ibnu Sina Biomedia 3(1): 11.

Munggaran, R. D. (2012). Pemanfaatan Open Source Software Pendidikan Oleh Mahasiswa Dalam Rangka
Implementasi UndangUndang No. 19 Tahun 2002 Tentang Hak Cipta. Skripsi. Program Sarjana Teknologi Pendidikan Universitas Pendidikan Indonesia. Bandung.

Notoatmodjo, S. (2018). Metodologi Penelitian Kesehatan. Jakarta: Rineka Cipta.

Oktarlina, R. Z., Ariyanti, P. R., Farmasi, B., Kedokteran, F., Lampung, U., Studi, P., Dokter, P., Kedokteran, F., \& Lampung, U. (2019). Hubungan Pengetahuan Mahasiswa Terhadap Penulisan Resep yang Baik dan Benar pada Mahasiswa Tahun ke 4 Fakultas Kedokteran Universitas. Jurnal Fakultas Kedokteran Universitas Lampung (6): 74-79.

Panjaitan, A P. (2017). Perbandingan Tingkat Pengetahuan Mahasiswa Kepaniteraan Klinik RSUD dr. H. Abdoel Moeloek Bandar Lampung dan Dokter Baru Lulusan UNILA 2016 Terhadap Penulisan Resep yang Benar. Skripsi. Program Studi Pendidikan Dokter Universitas Lampung. Bandar Lampung.

Pratiwi, W. R., Kautsar, A. P., \& Gozali, D. (2017). Hubungan Kesesuaian Penulisan Resep dengan Formularium Nasional Terhadap Mutu Pelayanan pada Pasien Jaminan Kesehatan Nasional di Rumah Sakit Umum di Bandung. Pharmaceutical Sciences and Research, 4(1), 48-56. https://doi.org/10.7454/psr. v4i1.3713

Ristekdikti. (2018). Potret Pendidikan Kedokteran di Indonesia dalam Menghadapi Tantangan Era Revolusi Industri 4.0. https: / /lldikti1.ristekdikti.go 
. id/details/apps/1235. $\quad 1$ Oktober 2020(09.41)

Romadhoni, M F. (2020). Kaidah Penulisan Resep. Yogyakarta : Deepublish Publisher.

Scott, L. (2016). Medication errors. In Nursing standard (Royal College of Nursing (Great Britain) : 1987) (Vol. 30, Issue 35).

https://doi.org/10.7748/ns.3 0.35.61.s49

Sugianto, I. M., dan Lisiswanti, R. (2016). Tingkat self directed learning readiness (SDLR) pada Mahasiswa kedokteran. Jurnal Majority, 5(5), 27-31.

Sujarweni, W P. (2019). Metodologi Penelitian Edisi 1. Yogyakarta:

Pustakabarupress.

Thenrajan, P., \& Murugan, Pr. (2016). Impact of patientbased teaching in improving prescription writing skills of II MBBS students. International Journal of Applied and Basic Medical Research, 6(3), 174. https://doi.org/ 10.4103/222 9-516x.186954

Yumniyati, K. (2016). Pengaruh Jenis Kelamin Terhadap Kemampuan Berpikir Kreatif Siswa Kelas $X$ pada Materi Geometri Dikontrol dengan Kemampuan Spasial Di SMA N 13 Semarang Tahun Pelajaran 2015/2016. Skripsi. Fakultas Sains dan Teknologi Universitas Islam Negeri Walisongo, Semarang. 